Journal Homepage: $-\underline{w w}$.journalijar.com
INTERNATIONAL JOURNAL OF
ASDVANCED RESEARCH (IJAR)
Article DOI:10.21474/IJAR01/2858
DOI URL: http://dx.doi.org/10.21474/IJAR01/2858

RESEARCH ARTICLE

\title{
“AN OBSERVATIONAL STUDY TO COMPARE THE EFFECTS OF DEXMEDETOMIDINE AND ESMOLOL IN ATTENUATING THE HAEMODYNAMICRESPONSETOLARYNGOSCOPY ANDENDOTRACHEALINTUBATION"
}

Dr. Navdeep Singh (Resident PG) and Dr. Dinesh Chauhan ( Professor).

Dept. Of AnaesthesiaSbks Medical Institute \& Research Centre SumandeepVIdyapeeth, Piparia, Vadodara. Gujrat, India, Pin -391760 .

\section{Manuscript Info}

\section{Manuscript History}

Received: 21 November 2016

Final Accepted: 21 December 2016

Published: January 2017

Key words:-

Dexmedetomidine, Esmolol,

hemodynamics, endotracheal intubation, laryngoscopy.

\section{Abstract}

Background: Laryngoscopy and intubation causes catecholamine release leading to sympathetic overdrive, resulting in hypertension and tachycardia. Different agents have been tried to overcome these responses over the years.

Aims: To compare an alpha- 2 agonist, Dexmedetomidine, with Esmolol, a beta blocker and to observe which of two is more proficient in suppressing this hemodynamic response.

Settings \& Design: Randomized, observational and a prospective study.

Subjects \& Methods: Sixty patients scheduled for general anesthesia were divided into two groups, D (Dexmedetomidine $1 \mathrm{mcg} / \mathrm{kg}$ ) and $\mathrm{E}$ (Esmolol $2 \mathrm{mg} / \mathrm{kg}$ ), received either drug as an intravenous premedication over 10 minutes before laryngoscopy and endotracheal intubation. Systolic, diastolic, mean arterial pressures and heart rate were measured at various time points. Percentage change of parameters at those time points from the baseline were compared between groups.

Statistical Analysis Used: Demographics and hemodynamic parameters were compared for groups by one way (ANOVA) ANALYSIS OF VARIANCE. Paired $t$-test was used for comparison between groups, while for comparison within groups, unpaired $t$-test was used. Probability was said to be significant if $\mathrm{p}$ value was less than 0.05. Data was represented in mean and SD.

Results: Percentage change of hemodynamic parameters from base line were less in Dexmedetomidine group than in Esmolol group. Statistically significant differences were observed between the two groups at time points within 1 minutes after laryngoscopy and endotracheal intubation.

Conclusions: Dexmedetomidine was more effective than Esmolol in attenuating the hemodynamic responses to laryngoscopy and tracheal intubation. 


\section{Introduction:-}

Laryngoscopy and endotracheal intubation are one of the two most important integral parts of anaesthetic management and critical care since their description by Rowbotham and Magill in 1921. Laryngoscopy and endotracheal intubation provides control of airway during general anaesthesia. Laryngeal and tracheal stimulation causes circulatory response, was known since 1940 (Reid and Brace) ${ }^{[1]}$ The mechanism behind hypertension and tachycardia, is an increased sympathetic action due to increased catecholamine release ${ }^{[2]}$ and mechanical stimulus causing reflex responses in cardio-respiratory systems. ${ }^{[3]}$ The increase in heart rate (HR) and blood pressure is usually variable, transient and unpredictable which may not be much significance in healthy individuals but can be detrimental in those with hypertension, cardiac dysfunction, coronary vessel disease or cerebro- vascular disease. Laryngoscopic and tracheal intubation responses in such individuals can precipitate coronary insufficiency, arrhythmias, pulmonary edema, left ventricular failure and cerebral hemorrhage. ${ }^{[4]}$

Various non pharmacological and pharmacological methods are in vogue to control this hemodynamic response. Opioids, local Anaesthetics, vasodilating agents and adrenergic blocking agents have been used to attenuate the pressor response. ${ }^{[5-13]}$ Alpha2 agonists, recently have gained significance in suppressing the laryngosympathetic responses. ${ }^{[14]}$ Dexmedetomidine is an $\alpha-2$ adrenergic receptor agonist, with particularly more prominent effects on cardiovascular system.SrivishnuVardhanYallapragada ${ }^{(15)}$ et $\boldsymbol{a l}$, in 2016, concluded that, Dexmedetomidine $(0.5$ $\mathrm{mcg} / \mathrm{kg})$ is superior to esmolol $(0.5 \mathrm{mg} / \mathrm{kg})$ in attenuating the hemodynamic response to laryngoscopy and tracheal intubation.Among the ßadrenergic receptor antagonist drugs, Esmolol is one of the most effective modality in minimizing the cardiac responses to laryngeal stimuli because of its ultrashort action (9 mins) and it can be administered intravenously. While it is an inhibitor of receptors of myocardium, receptors on smooth muscles of bronchial and vessel walls are also inhibited at higher $\operatorname{doses}^{[16]}$ SVReddy ${ }^{(17)}$ etalin2014, concluded that Dexmedetomidine $1.0 \mu \mathrm{g} / \mathrm{kg}$ provideda moreconsistent, and effectivediminisionofhaemodynamicresponseascompared toEsmolol $2.0 \mathrm{mg} / \mathrm{kg}$. Thus, we soughted to compare the effects of both these drugs in countering the exaggerated sympathetic responses secondary to laryngoscopy and endotracheal intubation.

\section{Materials and Methodology:-}

60 patients belonging to ASA I \&II, of either gender, in age group $18-65$ yrs posted for elective non- cardiac surgery were included in the study. Exclusion criteria- Patients with cardiovascular system pathologies, drug allergies, H/o bronchial asthma, on beta blocker treatment.

Preanaesthetic preparation- Patients were fasted preoperatively since $10 \mathrm{pm}$, night before surgery.

On the day of surgery, on the operation table, baseline parameters including Heart Rate (HR), SPO2, Diastolic blood pressure (DBP), Systolic blood pressure (SBP) and Mean arterial pressure (MAP) were recorded using standard ECG, NIBP \& SPO2 monitors. IV cannula was secured and all the patients were pre-loaded with Ringer lactate 10 $\mathrm{ml} / \mathrm{kg}$. All patients were premedicated using Injglycopyrolate $0.004 \mathrm{mg} / \mathrm{kg}$, Inj midazolam $0.02 \mathrm{mg} / \mathrm{kg}$ and injondansetron $0.08 \mathrm{mg} / \mathrm{kg}$, intravenously on arriving in operation theatre. They were randomly allocated into two groups by chit method. The study groups received either $2 \mathrm{mg} / \mathrm{kg}$ of Esmololiv or $1 \mu \mathrm{g} / \mathrm{kg}$ of Dexmedetomidine iv, all made in a $10 \mathrm{ml}$ disposable syringe diluted upto $10 \mathrm{cc}$ with normal saline. The drug were administered as a 10 minutes iv infusion. After injecting the study drug, All study parameters were recorded again after 10 minutes.

\section{Anaesthesia Technique:-}

Patients were pre-oxygenated with $100 \%$ oxygen for three minutes. Induction was done with Inj.Thiopentone sodium $6 \mathrm{mg} / \mathrm{kg}$ iv and endotracheal intubation was facilitated with Inj succinylcholine $2 \mathrm{mg} / \mathrm{kg}$ iv. All parameters were recorded after induction. Laryngoscopy and endotracheal intubation were performed by single investigator by the use of a rigid laryngoscope with standard Macintosh blade \& with appropriate sized, disposable, high volume, low pressure, cuffed tracheal tube. Laryngoscopy and intubation was done gently and in a single attempt. All study parameters were recorded for $1,3,5,7,10$, minutes of intubation. Anaesthesia was maintained with $\mathrm{O} 2(50 \%)$ 41 tr /min, N2O (50\%) 4ltrs /min, Isoflurane and inj. Atracurium. All surgical stimuli, analgesics supplements were avoided during the study. IV fluid were calculated and managed. Patients were reversed at the end of surgery, by intravenous inj Neostigmine $0.05 \mathrm{mg} / \mathrm{kg}$ and inj. Glycopyrolate $0.01 \mathrm{mg} / \mathrm{kg}$ iv. 


\section{Statistical analysis:-}

The data was analyzed using Student's T Test for intergroup comparison and all statistical methods were carried out using the chi-square test. The results were considered statistically significant when the [probability] $\mathrm{p}$ value $<0.05$.

\section{Results:-}

All 60 patients who were included were able to complete the study. The demographic data were comparable in terms of age, gender ratio \& ASA status for all the patients and there were no statistically significant differences in between the groups $(P>0.05)$. Baseline values of Heart Rate, Systolic Blood Pressure, Diastolic Blood Pressure and Mean Arterial Pressure were comparable in both Group D and Group E. Rise in mean Heart Rate after laryngoscopy and endotracheal intubation was observed in both the groups, although mean rise was minimal 2.39\% in Group D ( 2 beats) as compared to Group E, $8.40 \%$ ( 7 beats), which was highly significant $(P<0.05)$. Mean Heart rate between the two groups was found to be significant throughout the study period immediately after laryngoscopy and intubation. $(P<0.05)$. Furthermore, only in the Group D, there was no statistically significant increase in Heart Rate at any time interval.

Mean rise in systolic blood pressure [SBP] was minimal [1.65\%] in the D Group, as compared to the E Group [4.29\%], which was statistically significant $(P<0.05)$. Mean Systolic blood pressure between the two groups was found to be significant throughout the study period immediately after laryngoscopy and intubation $(P<0.05)$.

The DBP levels in both, Group D and Group E were comparable at all times after intubation. In both the groups, there was no significant rise in DBP following intubation $(P>0.05)$.

Mean blood pressure decreased after induction, but was not statistically significant in between Group D \& Group E. The MAP was raised by, $5.20 \%(4.8 \mathrm{mmHg})$ in Group D \& $5.89 \%(5.3 \mathrm{mmHg})$ in Group E at the time of intubation. Mean blood pressure was significant at 5, 7\& 10 minutes after intubation in between both groups. $(\mathrm{P}<0.05)$.

Table 1:- BASELINE (R1), HR, SBP, DBP \& MAP

\begin{tabular}{|c|c|c|c|c|c|}
\hline & \multicolumn{2}{|c|}{ GROUP D } & \multicolumn{2}{c|}{ GROUP E } & P Value \\
\hline HR & 80.73333 & 6.426955 & 81.3333 & 7.88442 & 0.7479 \\
\hline SBP & 123.0333 & 8.083544 & 124.6667 & 9.162643 & 0.4661 \\
\hline DBP & 75.36667 & 5.81605 & 74.7 & 5.608799 & 0.653 \\
\hline MAP & 91.3333 & 4.47470 & 90.9 & 4.071346 & 0.2834 \\
\hline
\end{tabular}

Table 2:-HEART RATE

\begin{tabular}{|c|c|c|c|c|c|}
\hline & \multicolumn{2}{|c|}{ GROUP D } & \multicolumn{2}{c|}{ GROUP E } & \\
\hline & MEAN & SD & MEAN & SD & P VALUE \\
\hline R1(BASELINE) & 80.7333 & 6.4269 & 81.333 & 7.8842 & 0.7479 \\
\hline R2(AFTER STUDY DRUG) & 84.9333 & 6.9328 & 85.8333 & 7.6568 & 0.635 \\
\hline R3(BEFORE INDUCTION) & 86.4666 & 6.9368 & 89.033 & 7.2658 & 0.1671 \\
\hline R4(1MIN) & 82.6666 & 6.1213 & 88.167 & 6.9087 & 0.0018 \\
\hline R5(3MIN) & 79.5666 & 6.4309 & 85.067 & 6.6173 & 0.0018 \\
\hline R6(5MIN) & 76.5667 & 6.2735 & 82.2 & 6.3213 & 0.001 \\
\hline R7(7MIN) & 73.9333 & 6.1134 & 79.667 & 5.7615 & 0.0004 \\
\hline R8(10MIN) & 71.4667 & 6.6214 & 77.7 & 5.9257 & 0.0003 \\
\hline
\end{tabular}


Table 3:-Systolic Blood Pressure

\begin{tabular}{|c|c|c|c|c|c|}
\hline & \multicolumn{2}{|c|}{ GROUP D } & \multicolumn{2}{c|}{ GROUP E } & \\
\hline & MEAN & SD & MEAN & SD & P VALUE \\
\hline R1(BASELINE) & 123.0333 & 8.0835 & 124.67 & 9.1626 & 0.4661 \\
\hline R2(AFTER STUDY DRUG) & 133.0667 & 7.9564 & 132.93 & 6.8528 & 0.9434 \\
\hline R3(BEFORE INDUCTION) & 134.1 & 6.7688 & 135.27 & 5.9939 & 0.4813 \\
\hline R4(1MIN) & 125.0667 & 7.6425 & 130.03 & 5.875 & 0.0066 \\
\hline R5(3MIN) & 118.8333 & 7.9701 & 125.33 & 5.7735 & 0.0006 \\
\hline R6(5MIN) & 112.3333 & 7.9928 & 120.97 & 5.5054 & 0.0001 \\
\hline R7(7MIN) & 106.7666 & 6.7705 & 116.77 & 5.835 & 0.0001 \\
\hline R8(10MIN) & 103.3333 & 5.9615 & 113.13 & 5.9058 & 0.0001 \\
\hline
\end{tabular}

Table 4:-Diastolic Blood Pressure.

\begin{tabular}{|c|c|c|c|c|c|}
\hline & \multicolumn{2}{|c|}{ GROUPD } & \multicolumn{2}{c|}{ GROUP E } & \\
\hline & MEAN & SD & MEAN & SD & P VALUE \\
\hline R1(BASELINE) & 75.3667 & 5.81605 & 74.7 & 5.6088 & 0.653 \\
\hline R2(AFTER STUDY DRUG) & 77.3333 & 5.88002 & 77.933 & 5.589 & 0.687 \\
\hline R3(BEFORE INDUCTION) & 79.2333 & 5.99818 & 79.633 & 5.3077 & 0.7856 \\
\hline R4(1MIN) & 79.0666 & 5.58281 & 79.933 & 5.699 & 0.5543 \\
\hline R5(3MIN) & 79.1 & 5.34563 & 79.833 & 5.2397 & 0.5938 \\
\hline R6(5MIN) & 77.1333 & 5.17775 & 77.433 & 5.6853 & 0.8317 \\
\hline R7(7MIN) & 74.3 & 5.29899 & 74.9 & 5.5544 & 0.9644 \\
\hline R8(10MIN) & 73.1666 & 5.11308 & 73.6 & 5.8875 & 0.7619 \\
\hline
\end{tabular}

Table 5:-Mean Arterial Pressure.

\begin{tabular}{|c|c|c|c|c|c|}
\hline & \multicolumn{2}{|c|}{ GROUP D } & \multicolumn{2}{c|}{ GROUP E } & SD \\
\hline & MEAN & SD & MEAN & VALUE \\
\hline R1(BASELINE) & 92.16667 & 4.948586 & 90.9 & 4.0713 & 0.2834 \\
\hline R2(AFTER STUDY DRUG) & 94.13333 & 4.439116 & 95.993 & 4.2906 & 0.1044 \\
\hline R3(BEFORE INDUCTION) & 96.76667 & 4.360349 & 97.967 & 4.064 & 0.2746 \\
\hline R4(1MIN) & 96.966667 & 4.25467964 & 96.267 & 4.2583 & 0.5269 \\
\hline R5(3MIN) & 94.066667 & 4.3702232 & 94.633 & 3.7736 & 0.5932 \\
\hline R6(5MIN) & 88.73333 & 4.3146369 & 91.5 & 3.5792 & 0.009 \\
\hline R7(7MIN) & 84.96667 & 4.3902976 & 88.667 & 3.8893 & 0.001 \\
\hline R8(10MIN) & 82.866667 & 3.9630477 & 86.6 & 4.1072 & 0.0007 \\
\hline
\end{tabular}

\section{Discussion:-}

Laryngoscopy and endotracheal intubation violates the patient's protective airway reflexes and this noxious airway stimuli leads to cardio-vascular responses initiated by proprioceptors responding to the supraglottic and the tracheal tissue irritation. ${ }^{(\mathbf{1 8})}$ These proprioceptors consist of mechanoreceptors which are located in close proximity to the airway mucosa, with the small-diameter myelinated fibers, slowly-adapting stretch receptors with large-diameter myelinated fibers, and nonmyelinated nerve fibers'spolymodal endings. ${ }^{(19)}$ These impulses to brainstem are transmitted to the glossopharyngeal and vagal afferent nerves, which in turn, causes the widespread autonomic activation through the sympathetic and parasympathetic nervous systems. Deeper planes of anaesthesia using the inhalational agents; topical lignocaine sprays, calcium channel blockers, vasodilators such as sodium-nitroprusside; nitroglycerine and narcotics etc are used as prophylaxis ${ }^{[20]}$ but hypotension, bradycardia, sedation and respiratory depression, are some of their prominent side-effects.

Esmolol, among the $\beta$-adrenergic blocking agents, appears to be an appropriate pharmacological agent for minimizing haemodynamic responses to laryngoscopy and endotracheal intubation, as it is more cardio-selective, with a rapid onset and ultra short elimination half-life. Several studies, describing the effects of Esmolol, on both Heart Rate and Blood Pressure during laryngoscopy and endotracheal intubation when compared to control, have been done in the past. Miller $\boldsymbol{e t} \boldsymbol{a l ^ { [ 2 1 ] }}$ reported that Esmolol when given as a single bolus dose of $100 \mathrm{mg}$, was

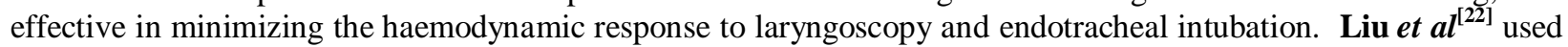


infusion of esmolol and found that rise was 50\% lower in patients treated with esmolol when compared to the control group.

Similarly, in our study, we found that, there was a rise in mean heart rate after laryngoscopy and endotracheal intubation in both study groups. Mean rise was less [2.39\%] in Group D as compared to Group E [8.40\%] which was statistically highly significant $(P<0.05)$. Mean Heart rate between the two groups was found to be significant throughout the study period immediately after laryngoscopy and intubation $(P<0.05)$.

Dexmedetomidine, directly acts on $\alpha_{2}$-adrenoceptor agonists and clinically have significant effects on the requirement of anaesthetic agents and on haemodynamic responses or the sympatho-adrenal responses which occurs during laryngoscopy and anaesthesia induction by Anaesthesia and surgery. Scheinin $\boldsymbol{e t} \boldsymbol{a l} \boldsymbol{l}^{[23]}$ suggested that Dexmedetomidine when given in a dose of $0.6 \mathrm{mcg} / \mathrm{kg}$, reduces, but not totally abolishes, the pressor responses to laryngoscopy and endotracheal intubation in young \& healthy individuals. Keniya et al ${ }^{[24]}$ concluded from their study that Dexmedetomidine $1.0 \mathrm{mcg} / \mathrm{kg}$ when used as pre-medication, minimized, but not totally obtunded the cardio-vascular responses to endotracheal intubation after anaesthesia induction.

In our study, we found that there was increase in mean SBP after laryngoscopy and intubation in both the groups, but the mean increase was minimal 1.65\% in Group D when compared with Group E, 4.29\%, which was statistically significant $(P<0.05)$.

The Diastolic Blood Pressure levels in both, Group D and Group E were comparable at all times after intubation. In both the groups, there was no significant rise in DBP following intubation $(P>0.05)$.

In our study, we infused Dexmedetomidine at a dose of $1 \mathrm{mcg} / \mathrm{kg}$ and Esmolol at $2 \mathrm{mg} / \mathrm{kg}$, both over a period of 10 min, before induction, when compared to study mentioned above, we found that the mean arterial pressure decreased, but was statistically not significant in between Group D and Group E. The MAP raised by, 5.20\% (4.8 $\mathrm{mm} \mathrm{Hg}$ ) in Group D and $5.89 \%(5.36 \mathrm{~mm} \mathrm{Hg})$ in Group E during intubation. MAP was found to be significant at 5, $7 \& 10$ mins after intubation in between both the groups $(\mathrm{P}<0.05)$.

In our study, we did not observe either bradycardia or hypotension in any of the patients in both the study groups.

\section{Conclusion:-}

In constraints of our study, we conclude that, Dexmedetomidine $1 \mathrm{mcg} / \mathrm{kg}$ IV as $10 \mathrm{~min}$ infusion, more effectivelydiminishes the pressor stress responses tolaryngoscopy and endotracheal intubation comparedto Esmolol $2 \mathrm{mg} / \mathrm{kg}$ IV without any deleteriouseffects.

\section{References:-}

1. Reid LC et al. (1940) Irritation of respiratory tract and its reflex effect on heart rate. SurgGynaec Obstet;70:157- 62.

2. Kovac AL.(1996) Controlling the hemodynamic response to laryngoscopy and endotracheal intubation. J Clin Anesth;8:63- 79.

3. Hamaya Y, et al. (2000) Differences in cardiovascular response to airway stimulation at different sites and blockade of the responses by lidocaine. Anesthesiology.;93: 95-103.

4. Dalton B, et al (1972). Myocardial ischemia from tachycardia and hypertension in coronary heart disease- patients undergoing Anaesthesia. Annual Meeting. Boston: American Society of Anesthesiologists;. p. 201- 2 .

5. Fassoulaki A, et al (1983) Kaniaris P. Intranasal administration of nitroglycerine attenuates the pressor response to laryngoscopy and intubation of the trachea. $\mathrm{Br} \mathrm{J}$ Anaesth;5:49-52.

6. Stoelting RK.(1979) Attenuation of blood pressure response to laryngoscopy and tracheal intubation with sodium nitroprusside. Anesth Analg;58:116-9.

7. Mikawa K, et al (1990) The effect of nicardipine on the cardiovascular response to tracheal intubation. $\mathrm{Br} \mathrm{J}$ Anaesth;64:240-2.

8. Charuluxananan S, et al (2000) Nicardipine versus lidocaine for attenuating the cardiovascular response to endotracheal intubation. J Anesth 2000;14:77-81. 
9. Martin DE,et al (1982) Rosenberg H, Aukburg SJ. Low dose fentanyl blunts circulatory responses to tracheal intubation. AnesthAnalg;6:680-4.

10. Kosh, et al (1998) Small dose fentanyl: optimal dose of injection for blunting the circulatory responses to tracheal intubation. Anesth Analg;86:658-61.

11. Cork RC,et al (1984). Fentanyl preloading for rapid sequence induction of Anaesthesia. Anesth Analg;63; 63:60-4.

12. Lev R, et al (1994). Prophylactic lidocaine use preintubation: a review. J Emerg Med;12:499-506.

13. Jalonen J, et al (1997). Dexmedetomidine as an anesthetic adjunct in coronary artery bypass grafting. Anesthesiology;86:331-45.

14. Jaakola ML, et al (1991). The analgesic action of dexmedetomidine - A novel alpha 2- adrenoceptor agonist In healthy volunteers. Pain;46:281- 5.

15. SrivishnuVardhanYallapragada, et al 2014 et al.: Dexmedetomidine, esmolol, intubation response, laryngoscopic response, Anesthesia: Essays and Researches; 8(3);

16. Hussain AM, (2005) Efficacy of fentanyl and esmolol in the prevention of haemodynamic response to laryngoscopyand endotracheal intubation. J Coll Physicians Surg Pak;15:454-7.

17. SiddareddigariVelayudha Reddy, et al,(2014)Dexmedetomidine versus esmolol to attenuate the hemodynamic response to laryngoscopy and tracheal intubation: A randomized double-blind clinical study, IJABMR; 4(2): 95100 .

18. Miller CD,et al (1990): Intraveous lignocaine fails to attenuate the cardiovascular response to laryngoscopy and tracheal intubation. Br J Anaesth65 : $216-219$, .

19. Robinson N, et al (2001): In patients with head injury undergoing rapid sequence intubation, does pretreatment with intravenous lignocaine/lidocaine lead to an improved neurological outcome? A review of the literature .Emerg Med J $18: 453-457$.

20. Ben-Abraham R, et al (2000). Dexmedetomidine: A promising agent for anesthesia and perioperative care. Isr Med Assoc J. 2:793-6.

21. Miller DR, et al (1991): Bolus administration of esmolol for controlling the haemodynamic response to tracheal intubation: The Canadian MulticentreTrial . Can J Anaesth38 : 849 - 858.

22. Liu PL, et al (1986). Esmolol for control of increases in heart rate and blood pressure during tracheal intubation after thiopentone and succinylcholine. Can AnaesthSoc J;33:556-62.

23. Scheinin B, et al (1992). Dexmedetomidine attenuates sympathoadrenal responses to tracheal intubation and reduces the need for thiopentone and peroperative fentanyl. Br J Anaesth. 68:126-31.

24. Varshali M Keniya, et al (2011). Dexmedetomidine attenuates sympathoadrenal response to tracheal intubation and reduces perioperative anaesthetic requirement. Indian J Anaesth. 55(4): 352-357. 